

capacities. These capacities, argue researchers, are shared by all languages and include innately given word classes.

But in Tomasello's view, acquiring a first language entails mastering more than its grammar. It means learning to use the language to communicate, using the same resources that adult speakers do. The child's abstraction of grammatical rules, as sketched out in Chomsky's proposal, remains an important part of this task but, as Tomasello points out, it is unclear how quickly children identify such rules.

Tomasello presents a wealth of observation and argument in support of his approach. He appeals to recent linguistics research on constructions in syntax, and to psychological research on children's understanding of intentions and beliefs in others, on joint attention in communication, and on function-based distributional analyses and analogy in learning. He makes a compelling case for his view of acquisition as an alternative both to those linguistic accounts that have focused on grammar and on how much is innate, and to current 'connectionist' accounts by Jeffrey Elman and his colleagues that focus on the forms learnt but not on their meanings. He argues against the idea that there are different mechanisms for learning rule-based and irregular forms of language, and in favour of a single mechanism for learning both words and constructions. And, like many biologists, he cautions against assuming innateness without examining the alternatives.

Tomasello should make us think more, and more carefully, about language in social as well as cognitive terms, and to consider the roles of attention, memory and learning in the process of acquisition. But he also leaves many questions unanswered. For example, what are the units of language being learnt? How should one define them - the notion of clause, for example? When do children learn to rely on conventions - that "dog" designates the category of dogs in English, but "chien" does so in French? Did languages evolve in the kinds of settings where adults and infants first establish joint attention? How do children learn the meanings of words and constructions? How is the choice of a conceptual perspective by the speaker "that dog" or "that animal" - related to the build-up of common ground in conversation? How do children get rid of errors such as "comed" (for "came") or "me throw" (for "I want to throw it") in their speech? Are they attentive to corrections from adults, and if so, how? Are they, in fact, exposed to enough information about constructions to allow for learning?

These are all empirical questions that must be taken seriously. How children acquire language can no longer be presented as a thought-experiment about the language that is the product of acquisition: it demands concrete data and theory about the process of acquisition.

Eve V. Clark is in the Department of Linguistics, Stanford University, Stanford, California 94305-2150, USA. \section{Changing the world}

Niche Construction: The Neglected Process in Evolution by F. John Odling-Smee, Kevin N. Laland \& Marcus W. Feldman

Princeton University Press: 2003. 486 pp. $\$ 75, £ 49.95$ ( $h b k$ ); \$39.50, £26.95 (pbk)

\section{Laurent Keller}

"Niche construction changes our conception of the evolutionary process ... and should be regarded, after natural selection, as a second major participant in evolution." So argue the authors of this book as early as page 2 . But what exactly is niche construction? And if it's really so important, how could evolutionary biologists have neglected it for so long?

The concept of niche construction is relatively simple. All living creatures, through both their metabolism and their behaviour, actively change and control the world in which they live. Organisms choose habitats and resources; they construct nests, holes, burrows, webs or pupal cases; and they modify the chemical environment in which they live. These alterations, which occur at scales ranging from the extremely local to the global, inevitably modify some of the selection pressures acting on the organisms. And it is precisely this - the effects of an organism on its own environment - that the authors believe to be the important component that has been neglected by the conventional theory of evolution.

The concept that organisms bring about important changes in their environment that may in turn affect their fitness is not completely new, however. Charles Darwin had already made several potent observations to this effect. For example, in On the Origin of Species he states: "When a species, owing to highly favourable circumstances, increases inordinately in numbers in a small tract, epidemics - at least this seems generally to occur with our game animals - often ensue: and here we have a limiting check independent of the struggle for life." This observation is strongly reminiscent of one in Niche Construction in which the authors discuss how large-scale human aggregation resulting from the construction of villages, towns and cities may create new health hazards such as the spread of epidemics.

In the 1980s, several scientists pointed 


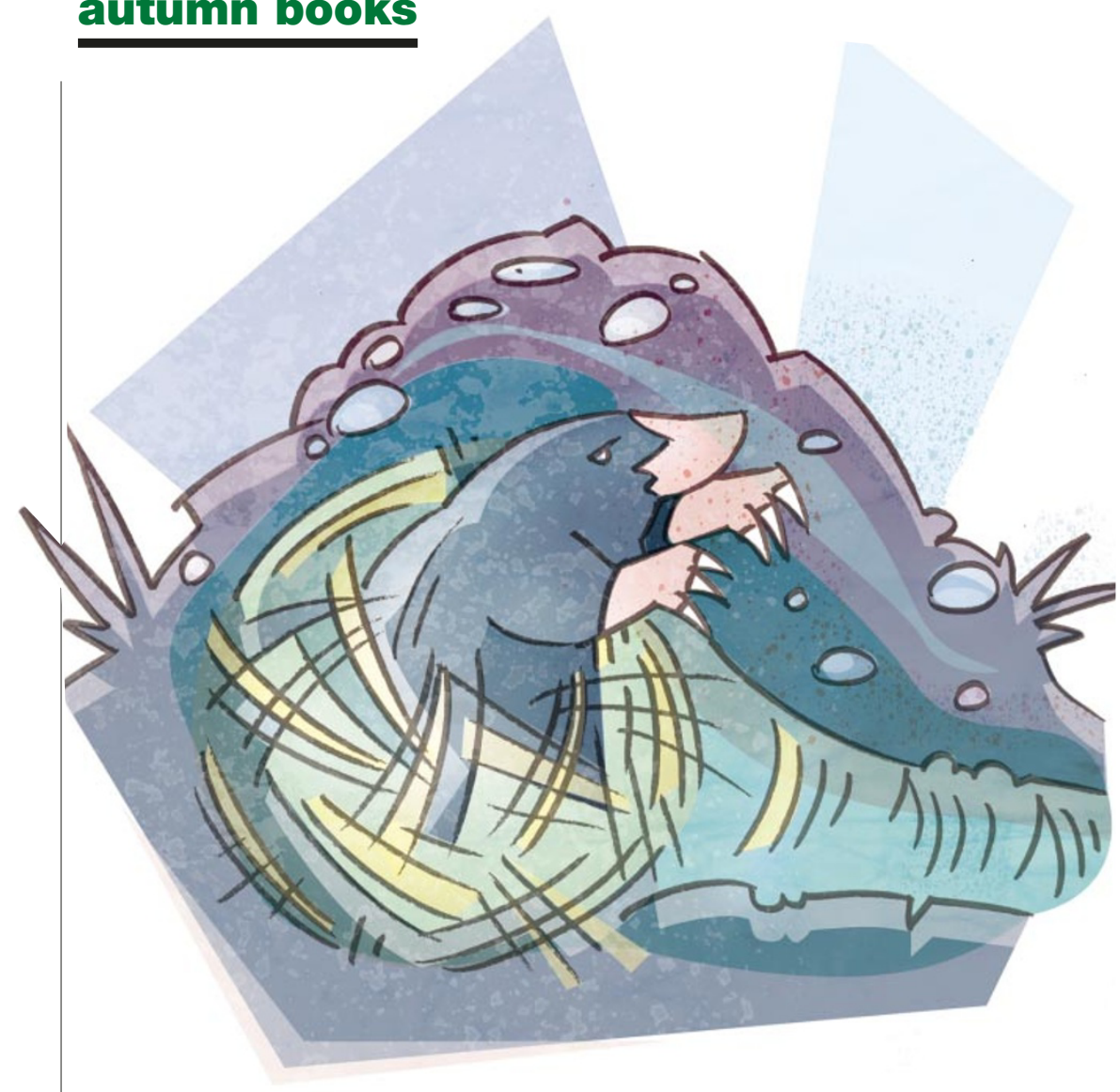

out that organisms not only adapt to their environment but construct it as well. In The Extended Phenotype (Freeman, 1982), Richard Dawkins argues that genes can express themselves outside the bodies of the organisms that carry them, an example being a beaver's dam. Richard Lewontin, in his contribution to Evolution from Molecules to Men (Cambridge University Press, 1983), also realized that the histories of organisms and the environment are a function of each other. He therefore suggested that what is actually happening in nature could be represented by a pair of coupled differential equations.

Niche Construction goes one step further by providing an exhaustive list of the possible effects of organisms on their environment, from the alteration of non-living environments to various sorts of maternal effects induced by differences in the levels of yolk, hormones and messenger RNA in the cytoplasm. In humans, cultural processes constitute an additional kind of non-genetic information that is transmitted from one generation to the next. The authors correctly argue that niche construction may result in evolutionary feedback, with the evolutionary trajectories of organisms being influenced by the changes that they induce on their environment. Feedback also occurs across generations, with individuals being influenced by the environmental modifications provoked by their ancestors.

To make their point, the authors list numerous examples. One of the most striking is the evolution of lactose tolerance. The domestication of cattle brought milk and dairy products into the diet of some human populations for enough generations to promote genes that confer greater lactose tolerance. Another example of a culturally induced genetic signature relates to the influence of agricultural niche construction on natural selection. The Kwa-speaking yam cultivators of West Africa made clearings in tropical rainforests, increasing the amount of standing water. This provided superior breeding grounds for malaria-carrying mosquitoes, which in turn increased the prevalence of malaria. At the same time, the frequency of the haemoglobin allele responsible for sickle-cell anaemia increased, as people who have one copy of this allele have some resistance to malaria. These examples demonstrate how cultural processes are not just a product of human genetic evolution but also a cause of it.

So does this mean that we need a new, extended theory of evolution as advocated by Niche Construction? I believe that the answer is no. First of all, the examples of niche construction given in the book can be explained by conventional evolutionary theory once all of the relevant environmental factors are taken into account. Several elegant models — including some developed by the authors themselves - have already been proposed to deal with feedback effects between organisms and their environment. At the same time, it is not possible to develop an extended theory of evolution that can encompass all of the different types of nicheconstruction effects. Interactions between organisms and their environment are, by their very nature, complex and result in an intricate web of interacting effects. No heuristic theory could integrate all of these effects without becoming intractable, so we need to devise specific models for each situation. Indeed, evolutionary biologists are already doing exactly this.

To summarize, Niche Construction does an excellent job of detailing the many ways in which organisms modify their environment and hence the selective forces acting on them. But it is unfortunate that the authors attempt to oversell the significance of niche construction. By advocating a grand, extended evolutionary theory, they distract readers from the more important message of the book, which is that the influence of organisms on their environment can have farreaching consequences. Indeed, humans are currently working hard at building a vivid example of this. By allowing the massivescale niche destruction that is currently under way, we are not only compromising the environment, but also affecting the prospects and evolutionary trajectories of our children and many later generations.

Laurent Keller is in the Department of Ecology and Evolution, Biology Building, University of Lausanne, 1015 Lausanne, Switzerland.

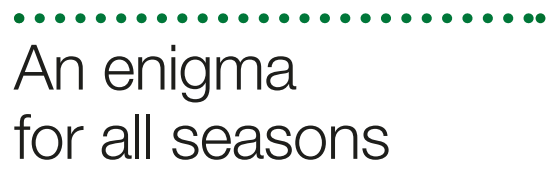

\section{Prof: The Life of Frederick \\ Lindemann}

by Adrian Fort

Jonathan Cape: 2003. 374 pp.

$£ 18.99$, Can $\$ 48.50$

\section{Stuart Young}

According to Mark Twain, "Biographies are but the clothes and buttons of the man the biography of the man himself cannot be written." Yet with so puzzling a subject as Frederick Lindemann, attempting to portray "the man himself" is difficult to resist. In the world of science he was exceptional, and in the world at war his power was as great as that of any scientist in history. But he could also be reticent and reclusive. Although former associates remember him well, to many others Lindemann remains, as was said of him recently, "the most important man you have never heard of".

Lindemann's cherished homeland was England, but his scientific education and early research took place in Germany, where he worked successfully on thermodynamic problems with Walther Nernst in Berlin. In 1911, aged just 25, Lindemann took part in 